\title{
Rota segura para dias de inundações: desenvolvimento de elementos visuais para auxiliar na locomoção, alertas e localização da população
}

Jean Fabyano Andrighi (Currículo Lattes) Virginia Grace Barros (Currículo Lattes)

\section{METODOLOGIA DE DESIGN APLICADA}

Para alcançar os objetivos propostos, o processo de pesquisa foi organizado conforme a metodologia para Sistema de Informação para Wayfinding (SIW) proposta por Calori (2007). Essa metodologia foi adaptada para atender ao estudo em questão. Para o presente projeto de pesquisa foram utilizadas as etapas de pré-design e design. Segundo Scariot (2013, p. 70), o pré-design consiste na coleta de todas as informações necessárias para o aprendizado e descoberta de aspectos específicos do projeto. Assim sendo, o pré-design se caracterizou pela fundamentação teórica do projeto em questão, apresentando os contextos relacionados aos riscos socioambientais 
e inundações no ambiente urbano, de que forma esses eventos afetam o município de Joinville (especificamente a área da bacia hidrográfica do rio (achoeira-BHRC), além de como surgiu e funciona o projeto Rota Segura para Dias de Inundações (RSDI). No segundo momento foram contextualizados os assuntos relativos à Wayfinding, sinalética, Design (informação e sinalização) e sinalização (normas e leis), os quais contribuem para reflexões acerca do tema em estudo.

A etapa de design apresenta duas subdivisões: o design esquemático e desenvolvimento de design. $O$ design esquemático consiste na determinação de locais a serem sinalizados e da função que se deseja com cada elemento da sinalização, gerando um esquema ou inventário preliminar do sistema. Nesse sentido foi possível ter uma visão geral do projeto, plano de localização dos elementos de sinalização (peças), hierarquia das mensagens, opções de tipografia, símbolos, contexto visual de cada peça, estudos básicos de modelos, formas e formatos, entre outros (SCARIOT, 2013). O design esquemático na pesquisa em foco analisou tanto a RSDI desenvolvida pela Defesa Civil quanto a BHRC a fim de chegar a um entendimento sobre como se comporta a mancha de inundação nessa área. Por meio dessa análise definiu-se uma área de estudo dentro da BHRC para a aplicação da proposta de sinalização. Posteriormente, diferentes mapas do Sistema Municipal de Informações Georreferenciadas (SIMGeo) foram cruzados (focados no recorte pré-estabelecido e no mapa da RSDI) e assim foram definidos os pontos a serem sinalizados, bem como quais seriam as sinalizações adequadas para cada situação. Esse processo foi acompanhado pela Defesa Civil de Joinville e apresentado ao Instituto de Pesquisa e Planejamento Urbano de Joinville (IPPUJ) e Departamento Municipal de Trânsito de Joinville (DETRANS-antigo Instituto de Trânsito e Transporte de Joinville-ITTRAN), os quais 
contribuíram com apontamentos e sugestões a partir de experiências técnicas/campo, possibilitando novas visualizações, alterando certos aspectos anteriormente definidos. A partir de tais análises foi iniciada a geração de alternativas, nomeada de desenvolvimento de design, que segundo Scariot (2013) corresponde à geração de alternativas, a partir da qual os fundamentos e informações visuais são formatados. Posteriormente as melhores alternativas são definidas e refinadas para representar o SIW. O desenvolvimento de design tem como objetivo apresentar o plano de localização final das peças, o inventário final de mensagens, os desenhos finais das peças gráficas e físicas e as especificações técnicas, entre outros.

\section{PRÉ-DESIGN}

O crescimento urbano é um fenômeno mundial. Nesse contexto, a constante ocupação das cidades por suas diferentes estruturas artificiais (estradas, ruas, casas, edifícios, indústrias etc.), em áreas que anteriormente eram reservadas ao meio ambiente natural, geram diversos problemas socioambientais, tais como poluição, doenças, falta de água, calor excessivo, inundações, entre outros. Em 1900, 13\% da população mundial era urbana, atualmente este percentual chega a 50\% (MULLER et al., 2012a). No Brasil, segundo Instituto Brasileiro de Geografia e Estatística (IBGE), as áreas urbanas possuem 23 milhões de habitantes e comportam $84,4 \%$ da população do país (SOUZA, 2013). As cidades muitas vezes são construídas sobre locais inadequados do ponto de vista urbanístico e ecológico. A esse respeito, Barbosa (2013) aponta que desastres naturais como enchentes, inundações e deslizamentos têm aumentado consideravelmente nas últimas décadas. $O$ processo de ocupação urbana não respeita o meio ambiente natural, englobando 
rios (aterrados ou canalizados), vegetação (derrubada), terrenos (impermeabilizados), encostas (ocupadas de maneira irregular), sem mencionar a poluição que contamina o solo e leito de diversas formas.

Nos últimos dez anos cerca de 250 milhões de pessoas foram afetadas por inundações e enchentes, sendo esses os riscos socioambientais mais generalizados e crescentes nas cidades ou assentamentos urbanos de diferentes tamanhos (UN/ISDR, 2013). Conorath (2012, p. 18) destaca que, “[...] ao redor do mundo, as inundações são responsáveis por $55 \%$ de todos os desastres registrados e por 72,5\% das perdas econômicas".

No Brasil, segundo Pizza (2013), 33 milhões de pessoas foram expostas a riscos de inundações até 2012, um número que poderá chegar a 43 milhões até 2030. O autor salienta ainda que as perdas econômicas promovidas por tais ocorrências poderão aumentar de US\$ 1,4 bilhão para US\$ 4 bilhões por ano, em menos de 20 anos, no Brasil. Comparadas com os dez anos anteriores, as ocorrências de desastres naturais no Brasil cresceram 268\% na década de 2000. As inundações foram o evento cuja frequência mais aumentou, sendo que as inundações bruscas tiveram $72 \%$ e as inundações graduais 80\% de aumento (CONORATH, 2012). Sausen e Narvaes (2013) destacam que o estado de Santa Catarina aparece quatro vezes na lista dos maiores desastres naturais do Brasil, em 1911, 1974, 1983 e 2008, esses eventos totalizaram um número de 30 mil mortos, entre inundações e deslizamentos.

O município de Joinville, situado na região norte do estado de Santa Catarina, possui aproximadamente 554 mil habitantes, sendo a maior cidade do estado em população, com uma densidade demográfica de 453 hab./ km². É o mais importante polo econômico, tecnológico e industrial do estado (JOINVILLE CIDADE EM DADOS, 
2014). Desde sua fundação em 1850 com a chegada dos imigrantes alemães, o município se desenvolveu numa região adversa, do ponto de vista urbanístico (SILVEIRA et al., 2009). Em uma região que apresenta clima tropical e subtroprical superúmido, com umidade relativa do ar atingindo uma média acima de 78\%, temperatura média anual de 22 graus centígrados, média pluviométrica mensal de 190,08 mm (SILVEIRA et al., 2009). Além de todos esses fatos já mencionados, durante os períodos de amplitude da maré verifica-se a inversão do fluxo da água do rio Cachoeira, principal bacia urbana da cidade (BHRC), até quase a metade de seu percurso, causada pelo ingresso de água salgada vinda através do canal da baía da Babitonga. Essa ocorrência pode causar inundações mesmo em dias sem chuvas, principalmente no centro da cidade, pois parte das margens do rio Cachoeira está apenas dois metros acima do nível do mar. Tais características fazem com que a cada três ou quatro anos (no período da lua cheia ou lua nova) ocorra no mínimo uma forte cheia, fazendo com que a cidade fique inundada tanto com a cheia do rio quanto pelo nível das marés (SILVEIRA et al., 2009).

Em 157 anos de história, 111 inundações atingiram a população de Joinville. Nesse sentido, Silveira et al. (2009) apontam que a bacia do rio Cachoeira foi a região em que se registrou a maior frequência das inundações (30\%).

De acordo com Muller et al. (2013b), a BHRC localiza-se na região urbana de Joinville tendo sua foz na baía da Babitonga, representando 7,3\% de área da região onde vive $49 \%$ da população. Eventos meteorológicos associados às marés astronômicas (marés altas) geram grandes inundações a cada dez anos, com uma média de 2,53 metros, podendo inundar $10,73 \mathrm{~km}^{2}$ da área urbanizada. Nesses eventos, o centro da cidade que correspondendo à BHRC tem 29,4 \% de sua área tomada pela inundação (JOINVILLE, 2011a). Muller 
(2012), em seus estudos, aponta que a BHRC tem 56\% de sua área situada em uma região suscetível a inundações categorizadas como altas e muito altas. $O$ alto índice de suscetibilidade a inundações dessa região, acrescenta Muller (2012, p. 84), relaciona-se diretamente com a geomorfologia da região,

[...] cujas feições geomorfológicas apresentam alta suscetibilidade a inundações (planície de maré, terraço fluvial, terraço lagunar e planície colúvio aluvionar, configurando as feições encontradas no fundo dos vales), associadas à altas taxas de impermeabilização do solo (áreas urbanizadas) e baixas declividades (<12\%).

Observando tais fatos, a Defesa Civil de Joinville, juntamente com outros órgãos municipais, estabeleceu uma Rota Segura para Dias de Inundações (RSDI) com mapa (Figura 1), com o intuito de possibilitar um trajeto livre de inundações para a população e visitantes. Essa ação visa auxiliar e orientar a população, prevenindo e reduzindo os riscos nos momentos das ocorrências de fenômenos adversos que atingem a região todos os anos.

Figura 1 - Recorte do mapa Rota Segura demonstrando a área central de Joinville e BHRC

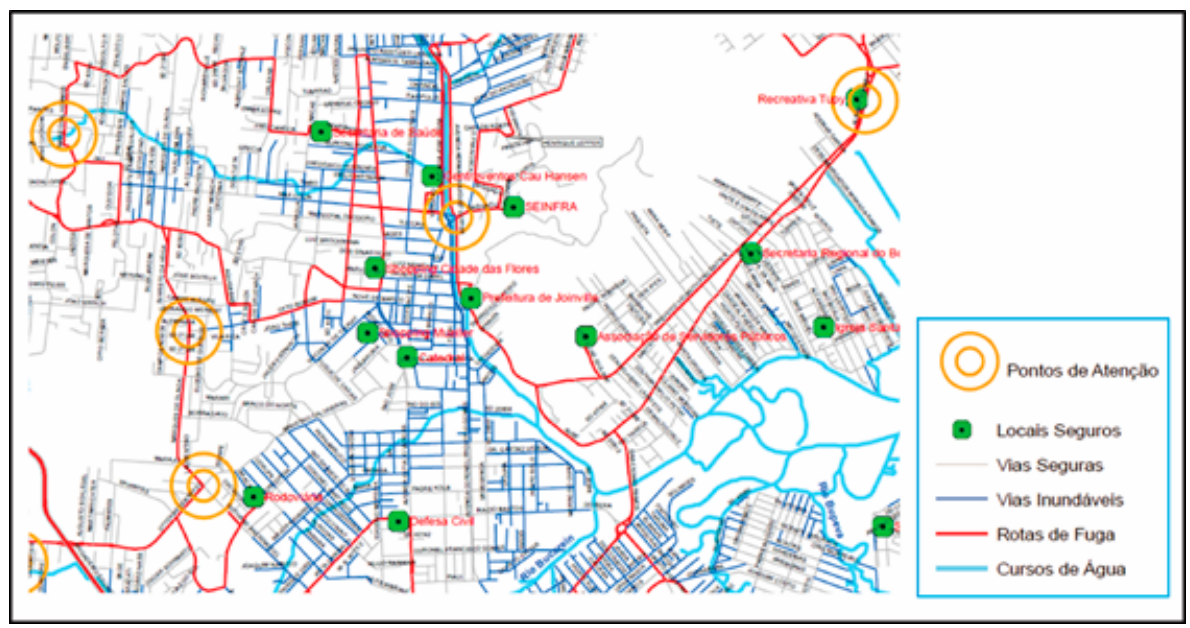

Fonte: Defesa Civil (2013) 
Entre as cidades brasileiras, a RSDI do município de Joinville é inovadora, sendo a única no país que apresenta uma rota tanto para área urbana quanto para a área rural. A rota, porém, não possui sinalizações ou elementos visuais que identifiquem o trajeto da rota, nem tampouco que orientem ou indiquem como chegar até ela, sendo esse o grande motivador para a definição de Joinville como foco dos estudos.

A partir do cenário apresentado, o desenvolvimento de uma proposta de Sistema de Informação por meio de elementos visuais se mostrou necessário como parte integrante do projeto da RSDI. A orientação feita por meio de elementos visuais torna o percurso mais claro e objetivo, fazendo com que os envolvidos se encontrem e se desloquem mais rapidamente nos momentos de risco de inundações, facilitando a orientação sem a necessidade de utilização de um mapa.

Nesse sentindo, conceitos atrelados à Wayfinding, sinalética, design (informação e sinalização) e sinalização (normas e leis) foram pesquisados. Segundo Scherer e Uriartt (2012), o termo Wayfinding surgiu em 1960 com Kevin Lynch e mais tarde foi retomado por Paul Arthur e Romedi Passini. Segundo os autores, o termo representa a relação dinâmica de uma pessoa com o espaço, constituindo-se como uma nova abordagem para estudar o processo de alcançar ou chegar a um destino, em um ambiente familiar ou não (ARTHUR; PASSINI, 2002). Baumann (2013) destaca que, além disso, ele é importante por mostrar informações em pontos estratégicos e também por guiar as pessoas na direção correta. Segundo Scariot (2013), com intuito de auxiliar o deslocamento em ambientes físicos e na construção dos mapas cognitivos, designers e outros profissionais constroem e organizam os espaços, introduzindo sistemas de SIW próprios para cada ambiente. 
Artefatos como mapas, placas, totens, sinais, luzes entre outros, podem ser utilizados para facilitar o processo de orientação do indivíduo. Tais artefatos, contudo, serão eficazes somente se o indivíduo conseguir interpretar as informações e relacioná-las com o ambiente em questão. $\mathrm{O}$ Wayfinding deve ser um meio eficiente no momento de englobar as informações, incluindo textos, pictogramas, mapas, fotografias, esquemas e diagramas, e os indivíduos devem observar, ler, aprender e compreender esses elementos para que possam concretizar sua movimentação (SCARIOT, 2013). Nesse sentindo, Caldeira (2013, p. 3) aponta que o Design de Sinalização (DS) tem como vocação criar informações para os indivíduos em meios urbanos ou arquitetônicos, entrando no grupo do chamado Design Gráfico Ambiental (DGA). Há de se observar que ele não está ligado somente a uma única área de conhecimento, pois envolve "[...] a intersecção entre design gráfico, design de produto, arquitetura, urbanismo e comunicação, com o intuito de informar, orientar, identificar e ambientar".

Dentro do espaço público (aberto) a redução da informação é essencial. Nesse contexto, o domínio de formas de linguagem básica prevalece e se mostra um meio a ser estudado para o momento de projetar sinais ou sistemas de sinalização para tais ambientes.

Sendo assim, Costa (2011a) aponta que a sinalética deve ser empregada, sendo ela uma das facetas do design de informação, e se trata de uma informação instantânea, inequívoca, utilitária, pois assim encontramos um determinado sinal que nos guia. A sinalética nos espaços públicos e os sistemas de sinalização urbana e viária coexistem, mas não são equivalentes. Os objetivos de um e de outro sistema são diferentes. A sinalética é um sistema criado para servir aos indivíduos, adaptando-se a cada ambiente ou problema específicosem exercer a força de leis e normativas, ela apresenta uma opção, 
com códigos de leitura parcialmente conhecidos, reforçando ou criando uma identidade para o ambiente. Já a sinalização objetiva regulamentar o fluxo de pessoas e veículos por meio de um sistema normativo e restrito, uniformizando todo o ambiente em que está inserida como, por exemplo, a sinalização viária (no Brasil estabelecida pelo Código de Trânsito Brasileiro - CTB) e de segurança (no Brasil estabelecida pela Norma Brasileira-NBR 13.434-2) (CALDEIRA, 2013).

Hunter (2013) reforça a ideia de que nos espaços públicos a sinalização deve ser organizada para transmitir informações aos indivíduos, considerando suas capacidades e permitindo que se locomovam e se localizem com facilidade. Dessa forma a sinalização se torna um processo de veiculação de informações com o objetivo de transmiti-las, por meio de sinais ou elementos visuais (linguísticos, cromáticos e icônicos), orientando e guiando os indivíduos nos diferentes espaços construídos (CARDOSO et al., 2014c).

Para que tal processo seja bem-sucedido no ambiente urbano, mostrando-se realmente eficiente dentro do que se pretende com ele, normativas e experiências de outras áreas do conhecimento (científico-técnico) devem ser consultadas. Sendo assim a partir de estudos teóricos, reuniões com diferentes órgãos públicos de Joinville foram realizadas.

\section{DESIGN}

A etapa de design teve início com a realização de reuniões com a Defesa Civil de Joinville e, posteriormente, com o IPPUJ e DETRANS para a apresentação do projeto e obtenção de informações e opiniões sobre o tema em estudo. Como resultado de tais encontros, foram estabelecidos objetivos para o projeto. A partir desses objetivos traçou-se um esboço do projeto, o qual foi apresentado no X Fórum 
Nacional da Defesa Civil do ano de 2013. Dessa forma, foi possível, a partir da conversa informal sobre o assunto, obter sugestões de diferentes agentes e técnicos dos diversos serviços de Defesa Civil Nacional. Além disso, foi possível identificar com eles a falta de projetos de sinalização com características voltadas aos processos de inundações no território brasileiro.

\section{DESIGN - DESIGN ESQUEMÁTICO}

Para o início dessa etapa foram analisados diferentes mapas utilizando Sistemas de Informação Geográfica e mapas gerados no município de Joinville, como parte do Sistema Municipal de Informações Georreferenciadas (SIMGeo), os quais foram disponibilizados por diferentes órgãos públicos do município de Joinville/SC (Defesa Civil, IPPUJ, Ministério da Fazenda, entre outros). Para a visualização da área da BHRC foram realizadas sobreposições dos mapas com as diferentes informações de interesse, o que possibilitou uma delimitação (recorte) mais específica dentro dessa área. Os mapas (ou camadas) utilizados para visualização da área a ser estudada foram o Rota Segura para Dias de Inundações, Limite de Bairros, Vias Urbanas e o da mapa da Mancha de Inundações da Bacia Hidrográfica do Rio Cachoeira (sub-bacia do rio Mathias) com tempo de reincidência de cinco anos. Com a sobreposição das camadas de informações, dos mapas e dos conhecimentos técnicos e de campo da Defesa Civil de Joinville foi possível delimitar uma área na BHRC (sub-bacia do rio Mathias), onde a incidência de inundações é frequente, sendo observado que esta possui um o alto índice de ruas no centro da cidade (aproximadamente 50 ruas), que situam-se em locais de risco, tendo cerca de $29,4 \%$ de sua área afetada pelas inundações (JOINVILLE, 2011a). 
Assim, foram identificados e definidos não apenas os pontos a serem sinalizados, mas também quais sinalizações deveriam ser utilizadas para cada situação. O processo de Wayfinding proposto por Gibson (2009), que consiste nas etapas de Informações Regulatórias, Informações de Orientação, Informações Direcionais e Informações de Indicação, foi aplicado na definição dos pontos a serem sinalizados, bem como para identificar quais sinalizações deveriam ser utilizadas em cada situação, pois o processo se aproxima da nomenclatura da CTB (2008), o que facilita a identificação desses pontos e das características específicas de cada um, sendo também um meio para definir as estruturas físicas de cada sinalização (totens, placas, artefatos luminosos, entre outros). Todas as definições dos pontos a serem sinalizados foram apresentadas, revistas e adequadas com a Defesa Civil de Joinville, DETRANS e IPPUJ. Recorda-se que todas as sinalizações, mesmo aquelas que não são comuns ao CTB (2008), devem manter suas regras básicas de posicionamento e diagramação, garantindo assim a sua eficácia e regularização.

A partir de então foram criados os elementos visuais para compor tais espaços, os quais deverão ser conectados ao sistema pluviométrico online da Defesa Civil de Joinville, que detecta em tempo real o aumento do nível das águas e que será o responsável por acionar os elementos automaticamente, tornando o sistema dinâmico e imediato no que se refere ao fornecimento de informação.

\section{DESIGN - DESENVOLVIMENTO DE DESIGN}

Após análises e definições sobre a área de estudo e os principais conceitos que o tema aborda, teve início o processo criativo para o desenvolvimento da sinalização para a RSDI. Primeiramente foram criados sinais visuais (pictogramas) que representassem os locais 
com risco de inundação na BHRC com base nas regras do CTB (2008) e alguns exemplos de placas. Posteriormente foi criado um logotipo para RSDI (Figura 2), sendo que o nome Rota Segura para Dias de Inundações foi alterado para Rota Segura de Inundações (RSI), tornando a leitura da informação mais rápida e simples (com base em conceitos de sinalética) para a população e facilitando também a sua aplicação em placas e sinalizações

Figura 2 - Logotipo para RSDI

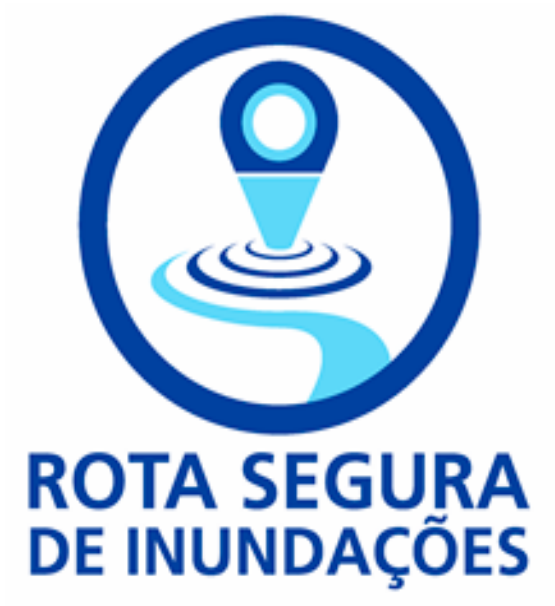

Fonte: elaborada pelos autores (2014)

Com a definição do logotipo para a Rota Segura de Inundações (RSI) aprovada pela Defesa Civil, foram criados os elementos visuais (totens) com características inspiradas no próprio logotipo. Estabeleceu-se, assim, um padrão visual que facilita a compreensão por parte dos usuários auxiliando de forma mais efetiva em sua locomoção com segurança durante as ocorrências de inundações. Além disso, os elementos estarão conectados ao sistema online de detecção automática (tempo real) do aumento dos níveis das águas da Defesa Civil (já em funcionamento), tornando-os mais dinâmicos e imediatos para informação. 
Os elementos visuais foram divididos em totens regulatórios de orientação iluminados e não iluminados, orientação para níveis de inundação iluminados, direcionais iluminados compostos por placas e compostos por setas, bem como sinalizações de indicação e sinalização auxiliar. Para a alimentação energética dos elementos, poderão ser utilizados, futuramente, sistemas de painéis solares com baterias, implantados na base de cada elemento ou em instalações próximas. Esses requisitos técnicos não serão aprofundados, uma vez que se trata de outra área do conhecimento e, para que tais explicações fossem efetivas, seria necessário enredar em um processo que fugiria do foco principal desta pesquisa.

Para todos os elementos criados, foram aplicados os contextos teóricos e técnicos estudados na fundamentação teórica, bem como as regras do CTB (2008) e de seus manuais estabelecidos pelo CONTRAN em 2007. Na Figura 3 será apresentado o exemplo de um dos elementos visuais (totens de orientação para níveis de inundação iluminados) criados e as explicações relacionadas às funções, materiais e composição. É importante salientar que os elementos foram baseados também em relação a sua altura com base na altura dos brasileiros (homens e mulheres), segundo última pesquisa de Orçamentos Familiares de 2002-2003 realizada pelo IBGE (IBGE, 2014).

Os totens de orientação para níveis de inundação iluminados (Figura 3) têm a função de informar e advertir sobre os níveis de inundação que atingem cada área, os materiais empregados em sua estrutura deverão ser o plástico ou acrílico, e seu formato em triedro (três vistas - facilitando a visualização de diferentes ângulos). As suas cores seguiram as normas do CTB (2008), bem como a NBR 13.434-2 para sinalizações de emergência. 
A área para o posicionamento desses totens foi definido com a Defesa Civil, IPPUJ e DETRANS:

- Totem de nível 1 (iluminação na cor azul): sinaliza as áreas livres de inundações, bem como o percurso da RSI;

- Totem de nível 2 (iluminação na cor laranja): sinaliza as áreas que merecem atenção, pois podem ser afetadas pelas inundações;

- Totem de nível 3 (iluminação na cor vermelha): sinaliza as áreas com alto risco de inundação.

Figura 3 - Totens de orientação para níveis de inundação - iluminados - 2D e 3D
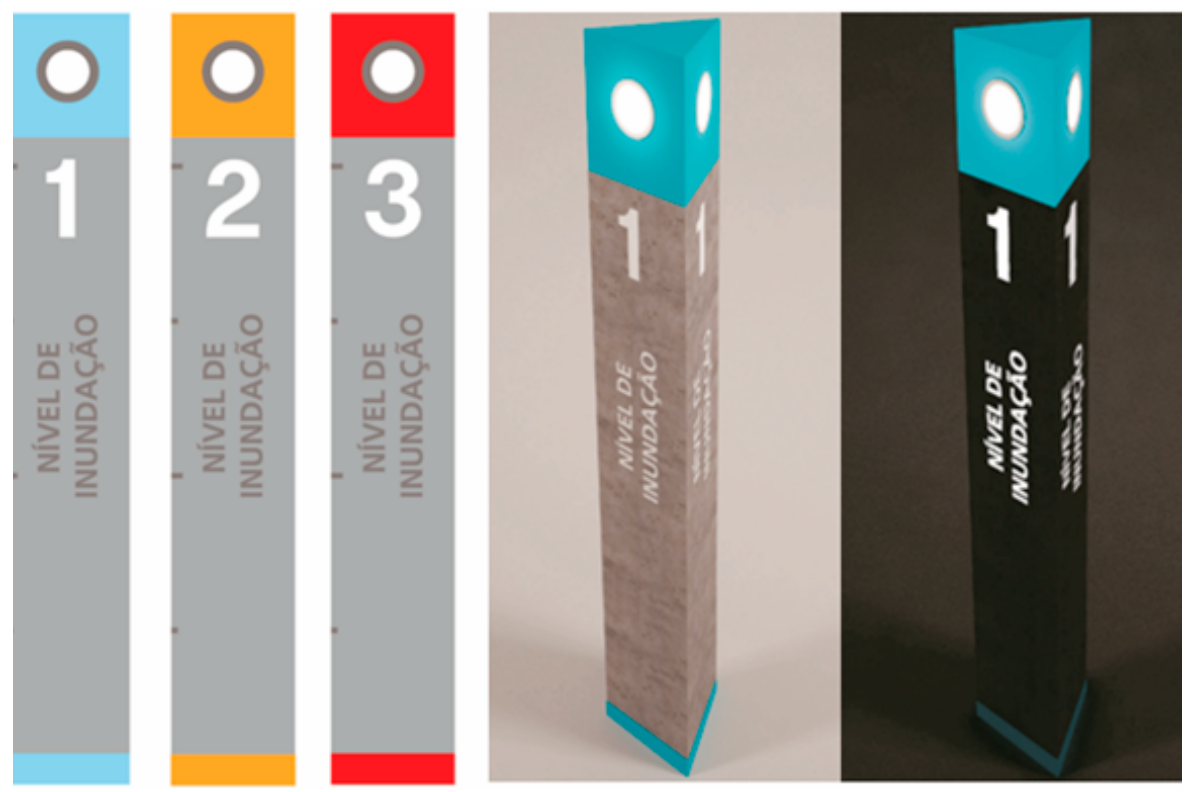

Fonte: elaborada pelos autores (2015)

Esses totens são compostos por três partes: 1) Base - será toda em plástico, com a função de sustentar o totem e comportar também em sua parte superior (no interior do totem, longe do alcance da água e vandalismos) os sistemas de energia e conexão wi-fi com o sistema pluviométrico online da Defesa Civil. Deve possuir também 
demarcações (traços) em seus cantos de meio em meio metro, indicando o nível da inundação. obs: Esse sistema de demarcação de nível de inundação foi solicitado pela Defesa Civil, pois esta compreende que tal medida é a mais coerente para a visualização dos usuários no momento da inundação. 2) Iluminação - na parte superior do totem se encontram os elementos luminosos em acrílico coloridos (translúcidos), com seus círculos transparentes para facilitar a saída da luminosidade. No interior desse elemento fica o sistema de iluminação por lâmpada fixa (estática). Este possui iluminação estática para não entrar em conflito com a informação luminosa dos totens de regulamentação que possuem um sistema de iluminação por giroflex. O elemento luminoso deverá ser encaixado no totem, facilitando sua remoção para manutenções, limpezas ou reposições. 3) Informações dos níveis de inundação - na parte superior do totem, abaixo da iluminação, ficam as numerações dos níveis de inundações. Tanto os números quanto os textos são retrorrefletivos a luz, sendo iluminados pela própria luz do totem.

Os totens de orientação para níveis de inundação iluminados deverão ser implantados próximos ao final das quadras das ruas, obedecendo aos posicionamentos e suas relações de distanciamento perante a via, estabelecidos pelo CTB (2008). Dessa forma, os usuários poderão visualizar a certa distância se estão fora ou dentro de uma área de risco, como também identificar, pela coloração luminosa dos totens, se estão se locomovendo de encontro ou saindo da área de risco.

\section{CONSIDERAÇÕES}

Os elementos visuais desenvolvidos para RSI, bem como para os momentos de inundações na BHRC (recorte), além de possibilitarem 
uma locomoção mais segura por parte dos envolvidos, estabelecem uma vivência com eles nos dias sem inundações, em virtude de suas configurações visuais e funções. Dessa forma, auxiliam também na visualização de locais seguros e com riscos de inundações antecipadamente, bem como nos momentos de inundações, alertando, orientando e indicando os caminhos a serem seguidos por meio de seus elementos luminosos. Pode-se apontar que uma das características mais marcantes do presente estudo está ligada à sua interdisciplinaridade, estabelecida com o DETRANS, IPPUJ e Defesa Civil de Joinville, que contribuíram para uma visualização voltada ao problema e objetivos do presente estudo, possibilitando também o conhecimento da complexidade que envolve a gestão do ambiente urbano, com ou sem a presença de inundações.

A vivência deste estudo possibilitou entender melhor como as inundações se comportam na área central do munícipio de Joinville, bem como conhecer como o DETRANS, IPPUJ e Defesa Civil de Joinville tratam esse processo no campo teórico e na prática. A partir desses conhecimentos e dos estudos teóricos realizados, foi possível contemplar todos os objetivos determinados para este trabalho.

Durante o processo da pesquisa foram encontradas duas dificuldades em específico. A primeira está relacionada à falta de pesquisas sobre sinalizações ou sobre como aplicá-las no ambiente urbano em momentos de inundações. A segunda se refere à complexidade em se desenvolver estudos como este, uma vez que são necessários os saberes técnicos e específicos de diferentes áreas do conhecimento, o que gera dificuldades ao pesquisador para contextualizar e processar todos os assuntos.

A falta de pesquisas na área de sinalização para momentos de inundações no ambiente urbano possibilita diferentes estudos futuros para área do design, bem como para as demais áreas do 
conhecimento. Nesse sentido, ressalta-se que a relação entre os conhecimentos configura-se como um ponto nevrálgico para a construção de tais processos de estudo e pesquisas.

A relevância social de projetos cujo foco é orientar e auxiliar as pessoas em momentos de risco de inundações se mostra evidente em virtude do crescimento dos centros urbanos e do consequente aumento na incidência dos desastres ambientais relacionados às inundações. Além disso, torna-se essencial suprir a falta de estudos nessa área quanto a planos urbanos focados em sinalizações para esse fim.

Sabe-se que muito ainda deve ser pesquisado em relação aos sistemas de sinalização para momentos de emergência com inundações em ambientes urbanos, principalmente pela inexistência de projetos nessa área em âmbito mundial. Nesse sentindo, o presente estudo também aponta a importância da evolução de tais estudos em diferentes áreas do conhecimento, além de ser um passo importante para o início de tais processos.

Espera-se que os elementos visuais desenvolvidos possam ser construídos, testados e analisados in loco, possibilitando assim, alterações e adequações, tornando-os mais eficazes dentro das funções que Ihes foram estabelecidas nesta pesquisa. 


\section{REFERÊNCIAS}

ARTHUR, P.; PASSINI, R. Wayfinding: people,signs and architecture. Ontario-Canadá, Focus Strategic Communications Incorporates, 2002.

BARBOSA, D. R. et al. Risco ambiental de enchentes nos rios formadores da f acia do rio Piabanha (região serrana Fluminense). Universidade Gama Filho, Pró-Reitoria de Humanidades e Ciências Sociais, Curso de Geografia. Rio de Janeiro, 2013.

BAUMANN, S. Intoduction to wayfinding and signage design. nov. 2010. Disponível em: <htttp://www.designworkplan.com/ wayfinding/introduction.htm>. Acesso em: 1 fev. 2013.

CALDEIRA, R. Comunicação e Práticas Semióticas nos Não lugares. Lisboa: Universidade de Lisboa. Faculdade de Letras de Lisboa, 2013.

CALORI, C. Signage and Wayfinding Design: a complete Guide to creating environmental graphic sesign systems. Nova lorque: Wiley John \& Sons, 2007.

CARDOSO, E. et al. Composição visual da vetas. Disponível em: <http://ndga.wordpress.com/2012/04/03/infograficos-sinalizacaoambientacao-2/> abril, 2012>.Acesso em: 06 jun. 2014.

CONORATH, G. D. Águas urbanas: análise morfométrica e hidrológica da bacia hidrográfica do rio Cachoeira - Joinville/SC. 2012 [incluir número de folhas]. Dissertação (Mestrado em [completar]) - MPPT/ FAED/UDESC, Florianópolis, 2012.

COSTA, J. Design para os olhos: marca, cor, identidade e sinalética. Tradução de Fernanda Soares. Lisboa: Dinalivro, 2011. 
CTB-CÓDIGO DE TRÂNSITO BRASILEIRO. Código de Trânsito Brasileiro: instituído pela Lei 9.503, de 23/09/97. 3. ed. Brasília: DENATRAN, 2008.

CONTRAN. Manual Brasileiro de Sinalização de Trânsito. V. I: Sinalização Vertical de Regulamentação. Brasília, 2007a.

- Manual Brasileiro de Sinalização de Trânsito. V. II: Sinalização Vertical de Advertência. Brasília, 2007b.

- Manual Brasileiro de Sinalização de Trânsito. V. III: Sinalização Vertical de Indicação. Brasília, 2007c.

- Manual Brasileiro de Sinalização de Trânsito. V. IV: Sinalização Horizontal. Brasília, 2007d.

Manual Brasileiro de Sinalização de Trânsito. V. V: Sinalização Semafórica. Brasília, 2007 .

- Manual Brasileiro de Sinalização de Trânsito. V. VI: Sinalização de Obras e Dispositivos Auxiliares. Brasília, $2007 f$.

GIBSON, D. The Wayfinding Handbook: information design for public places. Nova lorque: Princeton Architectural, 2009.

IBGE. Primeiros resultados: Brasil e grandes regiões. Disponível em:<http://www.ibge.gov.br/home/estatistica/populacao/ condicaodevida/pof/2002/>. Acesso em: 10 abr. 2014.

JOINVILLE CIDADE EM DADOS. Disponível em:

<https://ippuj.joinville.sc.gov.br/arquivo/lista/codigo/442-Joinville \%2BCidade\%2Bem\%2BDados\%2B2014.html>. Acesso em: 10 abr. 2014. 
JOINVILLE. Drenagem Urbana: Joinville enfrenta o desafio. Plano Diretor de Drenagem Urbana da Bacia Hidrográfica do Rio Cachoeira-PPDU. Joinville, 2011a.

MULLER, C. R. Avaliação de Suscetibilidade a Inundações utilizando Geotecnologias para a Bacia Hidrográfica do Rio Cachoeira - Joinville/SC. Universidade do Estado de Santa Catarina, Florianópolis, mai. 2012.

MULLER, C. R. et al. Ocupação em Joinville/SC e o Papel da Gestão Municipal para Mitigação de Dano Causados por Inundações. Revista Brasileira de Planejamento e Desenvolvimento, Santa Catarina, v. 1, n. 1, jul./dez. 2012a.

MULLER, C. R. et al. Bacias hidrográficas urbanas e a problemática das inundações-Estudo de caso: bacia hidrográfica do Rio Cachoeira - Joinville/SC. In: SIMPÓSITO BRASILEIRO DE SENSORIAMENTO REMOTO - SBSR, XVI, Foz do Iguaçu. Anais... Foz do Iguaçu, PR, Brasil: INPE, 13 a 18 abr. 2013b.

PEZZIN, O. C. Design de sinalização do Metrô de São Paulo: estudo de caso de sua manutenção. Faculdade de Arquitetura e Urbanismo, Universidade de São Paulo, São Paulo, 2013.

PIZZA. S. E. Brasil assimilou a importância do seguro contra riscos e inundações. Disponível em: <http://www.swissre.com/ latin_america/brasil_assimilou_importancia_seguro_contra_riscos_ inundacoes.html>. Acesso em: 24 nov. 2013.

SAUSEN, T. M.; NARVAES, I. S. Desastres naturais e geotecnologias: Inundações. Santa Maria, RS: INPE/CRS, 2013.

SILVEIRA, W. N. et al. História das inundações em Joinville: 18512008 - Curitiba: Organic Trading, 2009. 
SOUZA, E. Em 20 anos zonas urbanas do país crescem o equivalente a duas Xangai. Disponível em: <http://noticias.uol. com.br/cotidiano/ultimas-noticias/2011/04/29/em-20-anos-zonasurbanas-do-pais-crescem-o-equivalente-a-duas-xangai.htm $>$. Acesso em: 10 jun. 2013.

SCARIOT, C. A. Avaliação de sistemas de informação para wayfinding: um estudo comparativo entre academia e mercado em Curitiba, 2013. 179 f. Dissertação (Mestrado em Design) - Setor de Ciências Humanas, Letras e Artes da Universidade Federal do Paraná, 2013.

SCHERER, F.V.URIARTT, S. M.P.O uso da cor em sistemas de sinalização. In: CONGRESSO INTERNACIONAL DE ERGONOMIA E USABILIDADE DE INTERFACES HUMANO-TECNOLOGIA, 12., ago. 2012, Natal. Produto, informações e ambiente construído e transporte. Natal, RN, Brasil: [quem publicou], 2012.

UN/ISDR. International strategy for disaster reduction. Terminology on Disaster Risk Reduction. Disponível em: <http:// www.unisdr.org/>. Acesso em: 9 out. 2013. 
